\title{
THE WOLFSON FOUNDATION
}

\begin{abstract}
HE first report of the Wolfson Foundation, created in 1955, covers the first five years work of the Foundation*. So far, the Foundation has adopted as its principal aims the advancement of education and health in the United Kingdom and Commonwealth, with particular reference to scientific and technological education, building for higher educa. tion, youth activities, medical research and education, cancer research, and medical, surgical and nursing services not covered by the National Health Service. Up to July 1958 it was occupied by preliminary work, including the creation of the necessary administrative organization and a Board of Trustees of wide experience and enjoying general confidence. To November 30,1960 , grants totalling $£ 3,311,110$ had been made and grants totalling a further $£ 237,500$ were made in December 1960. These latter grants, which are listed on a separate sheet issued with the report, include $£ 100,000$ to St. Hilda's College, Oxford, for a residential block for 60 undergraduates, $£ 52,000$ in extension for three years of the $\$ 125,000$ already granted to the National Playing Fields Association, and $£ 5,000$ to the Commonwealth Society for the Deaf for a rehabilitation centre in Eastern Nigeria.

Grants for education noted in the report include $\mathfrak{£ 2 5 0 , 0 0 0}$ for a new Commonwealth Hall of Residence for 400 men students at the University of London; $£ 65,000$ to endow the Wolfson chair of metallurgy at the University of Oxford; and $£ 4,500$ for a research fellowship in metallurgy there; $£ 300,000$ for a hall of residence for about 150 men students at the University of Glasgow ; $£ 70,000$ for an assembly hall forming part of the main rlock of Churchill College, University of Cambridge, $£ 150,000$ for the establish. ment of the Institute of Criminology in the University of Cambridge ; $£ 75,000$ for building and furnishing the library of St. Catharine's College, Oxford;
\end{abstract}

* Report of the Wolfson Foundation, 1955-1960. Pp. 39 (8 plates) (I,ondon: The Wolfson Foundation, 1960.)
$£ 350,000$ to the Imperial College of Science and Technology to build and equip laboratories for biochemistry and chemical microbiology and support teaching and research in these subjects; $£ 210,000$ to the Royal Society to endow a research professorship; $£ 100,000$ to New Hall, Cambridge, and $£ 80,000$ to St. Anne's College, Oxford. A grant of $£ 2,000$ to the Royal Institution is a contribution to the Institution's work in interpreting current scientifio developments to the public.

Major grants in the field of health include $£ 250,000$ to the Westminster Hospital School of Nursing; $£ 150,000$ over 10 years to the British Empire Cancer Campaign in support of its researches; $£ 150,000$ to the Postgraduate Medical School, Hammersmith, for the Wolfson Institute containing lecture theatres, common rooms and other amenities for students and teaching staff; $£ 184,000$ for the Institute of Psychiatry associated with Maudsley Hospital, University of London; and $\$ 450,000$ to the Royal College of Physicians for a new building containing a larger library, a main lecture theatre seating 300 , a smaller lecture theatre, committee and common rooms, and a dining hall. A grant of $£ 22,000$ was made to Mr. Wylie McKissock, neurological surgeon at St. George's Hospital, London, for surgical research into anatomical and biochemical aspects of hæmorrhage of the brain.

A grant of $£ 10,000$ to the Royal Geographical Society is to be used during 1960-63 to encourage participation of young people in exploration. Miscellaneous grants include $£ 2,500$ to the Crofters' Commission, $£ 4,631$ to the British Museum to acquire a sculpture, discovered at Nineveh, showing Babylonian prisoners being carried off by the Assyrians, and $£ 2,500$ to the Justice Educational and Research Trust for an inquiry into the investigation of complaints against administrative and executive decisions.

\section{PUBLICATION OF CALORIMETRIC AND THERMODYNAMIC DATA}

$\mathrm{T}$ HE "Resolution on Publication of Calorimetric and Thermodynamic Date", which was adopted by the fifteenth Calorimetry Conference held at Gatlinburg, Tennessee, during September 7-10, 1960, is a revised and extended form of the similar resolution adopted by the eighth Calorimetry Conference held in 1953. It outlines minimum publication standards for the guidance of authors, editors and referees of articles on calorimetry, and states the author's first responsibility is to report his results in a form related as closely as possible to the experimentally observed quantities, with enough details of the experiments and auxiliary information to characterize the results completely. Derived or secondary data should never be published without the primary data on which they are based. The auxiliary informa. tion should include a complete description of the apparatus and procedures, with details of the reaction vessel or calorimeter, the temperature and time measuring systems, the calibration and sensitivity of the instrument used and the precision and accuracy of the results obtained ; the source and method of preparation of the samples studied, together with analyses and criteria of purity; and the values of the units and physical constants used in the coloulations.

One section of the resolution deals in some detail with the presentation of results, and gives recommendations for the thermochermical data, thermal data, and calculated thermodynamic functions which should be included in the description of certain important kinds of thermodynamic studies. It is pointed out that graphical or analytical representation of results is sometimes worth while for the convenience of the reader, but such representations seldom are a satisfactory substitute for tabular presentation of accurate experimental results. Where rough measurements made for technical purposes, or measurements on materials of undefined composition or by inferior techniques, are reported, they should be given minimum joumal space and the presentation should clearly recognize the lack of reliability of the results. 